\title{
Natural versus anthropogenic influence on trace elemental concentrations in precipitation at Dokriani Glacier, Central Himalaya, India
}

\author{
Shipika Sundriyal ${ }^{* 1}$, Tanuj Shukla ${ }^{2}$, Lekhendra Tripathee ${ }^{3}$, Dwarika Prashad Dobhal $^{4}$ \\ ${ }^{1}$ National Institute of Hydrology, 247667, Roorkee \\ ${ }^{2}$ Indian Institute of Technology, Kalyanpur, 208016, Kanpur \\ ${ }^{3}$ State Key Laboratory of Cryospheric Science, Northwest Institute of Eco-Environment and \\ Resources, Chinese Academy of Sciences, Lanzhou, Gansu \\ ${ }^{4}$ Centre for Glaciology, Wadia Institute of Himalayan Geology, 33 GMS Road, 248001, \\ Dehradun
}

\begin{abstract}
Atmospheric pollutants transport and deposition to the Himalayas could affect the climate, cryosphere, and monsoon patterns and impose an adverse impact on the Himalayan ecosystem. The data on trace elements (TEs) concentrations and dynamics over the high altitude Himalayan region is scarce and have received less attention. Therefore, in the present work, we investigated the TEs concentration and depositional pattern at Dokriani glacier, the central Himalayas to understand its levels, dynamics, and potential effects. A total of 39 samples were collected from two snow pit stratigraphies, deposited during non-monsoon period and monsoonal precipitation between 4530 to 4630 m.a.s.l altitudes in the year 2017. The results of analysed trace metals (Al, $\mathrm{Cr}, \mathrm{Mn}, \mathrm{Fe}, \mathrm{Sr}, \mathrm{Co}, \mathrm{Ni}, \mathrm{Cu}, \mathrm{Zn}, \mathrm{Cd}$, As and $\mathrm{Pb}$ ), showed high enrichment values for $\mathrm{Zn}, \mathrm{Cr}, \mathrm{Co}$, $\mathrm{Ni}$ and $\mathrm{Mn}$ compared to other parts of the Himalayan region, suggesting the influence of anthropogenic emissions (e.g., fossil fuel, metal production, and industrial processes) from urbanized areas of South Asia. Our results also revealed the possible health effects related to the enrichment of $\mathrm{Zn}$ and $\mathrm{Cd}$, which may be responsible for the skin-related diseases in the Uttarakhand region. We attribute increasing anthropogenic activities in the environment could have a significant impact on the ecosystem health in the central Himalayan region. This study provides the baseline information on TEs concentration and sources in the Himalayas, which needs wide dissemination to scientific as well as policymakers. Therefore, systematic observations, management, and preparing action plan to overcome the health effects from TEs pollution are urgently needed over the remote, pristine Himalayan region.
\end{abstract}

Keywords: Atmospheric pollutant, Anthropogenic inputs, Dokriani Glacier, Dry and wet deposition, Trace elements. 